\title{
O Símbolo em Paul Ricoeur: o mal, a hermenêutica e a religião
}

\author{
Lucas Andrade Ribeiro ${ }^{1}$
}

\section{RESUMO}

Este artigo visa elucidar facetas manifestas pelo símbolo na obra filosófica de Paul Ricoeur. Posto que neste encontra-se a chave para compreender questões aporéticas, buscando o aprofundamento do conhecimento científico, filosófico e religioso sem ter a intenção de esgotá-los. Mostrando, assim, a interação do símbolo com as temáticas do mal, da hermenêutica e da religião.

Palavras-chave: Paul Ricoeur; Símbolo; Mal; Hermenêutica; Religião.

\begin{abstract}
This article aims to elucidate facets manifested by the symbol in the philosophical work of Paul Ricoeur. Since this is the key to understanding aporetic issues in his thought, seeking to deepen scientific, philosophical and religious knowledge without the intention of exhausting them. Thus showing the interaction of the symbol with the themes of evil, hermeneutics and religion.
\end{abstract}

Keywords: Paul Ricoeur; Symbol; Evil; Hermeneutics; Religion.

\section{Introdução}

Esta pesquisa pretende dialogar sobre um dos aspectos mais ricos do pensamento do filósofo francês Paul Ricoeur: o símbolo. Em suas concepções este não é apenas algo que tem um sentido inequívoco ou mesmo estático, pelo contrário, para o autor, existe uma profunda riqueza de intepretações possíveis em cada um deles. Gerando um

1 Doutorando em Ciências da Religião pelo Programa de Pós-Graduação em Ciências da Religião da Universidade Metodista de São Paulo (Umesp). Bolsista CAPES. Mestre em Ciências da Religião pela Umesp. Graduado em Filosofia pela Universidade Estadual de Campinas (Unicamp), em Teologia pela Umesp, e em História pelo Centro Universitário Claretiano. E-mail: lucasandraderibeiro@gmail.com 
mundo de sentidos e significações, que deve ser explorado para a melhor compreensão do ser humano de si, da sociedade e do seu meio. Pois o "símbolo perde o seu carácter estático, entendido como sentido unívoco, passando a ser algo susceptível de interpretação e ganhando uma perspectiva mais ampla, enquanto refiguração textual e narrativa da experiência humana, da ação e do mundo." Denotando que o ser humano vive e se comunica, em grande medida, por suas mediações simbólicas. Hélio Gentil aponta os seguintes questionamentos: "não confundindo a multiplicidade de sentidos possíveis com a impossibilidade de um sentido? Não se estará confundido a ausência de um sentido a priori (...) com a ausência de todo sentido?"3 Isto é, comportar em seu pensamento a multiplicidade dos sentidos não significa, absolutamente, que não exista a possibilidade da construção de conhecimentos metodológicos e sistemáticos.

O pensador francês teve algumas fases na construção de seu pensamento, sendo que cada uma delas privilegiou a abordagem de uma temática. Uma das primeiras fases foi o período em que ele abordou questões concernentes ao mal, conteúdos estes manifestos entre os mais complexos para o filosofar. Cada uma de suas obras tendeu por encerrar-se com uma questão que introduzia um lampejo temático para o assunto a ser abordado na obra seguinte. Posto que "parece que cada um de meus livros quis responder a uma questão que se impõe com contornos bem definidos. E os livros que se seguiram vieram de questões não resolvidas pelos precedentes." ${ }^{4}$ Demonstrando, dessa maneira, que seu modo de trabalho buscou tratar problemas de alta complexidade sem se esquivar deles, ou mesmo sem pretender esgotá-los. E é justamente neste ponto que o símbolo se faz tão essencial.

Uma das grandes genialidades do autor foi sua capacidade de dialogar com temas relevantes para sua geração, bem como conciliar uma gama plural de influências filosóficas tendo a capacidade de formular

2 TAVARES, Manuel. "Paul Ricoeur e um novo conceito de interpretação: da hermenêutica dos símbolos à hermenêutica do discurso". In: Veritas. Porto Alegre, v. 63, n. 2, maio-ago. 2018. pp. 436-457. p. 445.

3 GENTIL, Hélio. "Paul Ricoeur e o desafio do sentido". In: CARDIM, Leandro Neves. Tópicos de filosofia francesa contemporânea. Curitiba: Ed. UFPR, 2014. p. 189.

4 RICOEUR, Paul. Escritos e Conferências II: hermenêutica. Tradução de Lúcia Pereira de Souza. São Paulo: Edições Loyola, 2011. p. 15. 
sínteses inovadoras e relevantes. Um dos casos onde vê-se esta questão é quando Ricoeur busca estabelecer um diálogo com à Fenomenologia da Percepção de Merleau-Ponty, em seus aspectos sobre as capacidades humanas analisadas pela perspectiva fenomenológica, e ao mesmo tempo estende sua gama de diálogos com seu conflito pessoal entre as obras de Husserl e Marcel, "ao primeiro eu devia a metodologia designada pelo termo da análise eidética (...) ao segundo devia a problemática de um sujeito ao mesmo tempo encarnado e capaz de manter seus desejos e poderes a distância." "Isto é, uma pessoa que seja senhora de si e servidora de suas necessidades figurada pelo caráter, pelo inconsciente e pela vida. Dando voz a um indivíduo responsável e ético.

Este artigo, então, visa apresentar múltiplas facetas que existem no símbolo, intercambiando a relação "entre hermenêutica e reflexão. Com efeito, não há símbolo que não suscite uma compreensão por meio de uma interpretação. Mas como é que esta compreensão pode estar ao mesmo tempo no símbolo e além?" Questionamento este que buscará ser elucidado, a medida do possível, em sua interação com o mal, com a hermenêutica e a com a religião.

\section{Símbolo e o Mal}

O problema do mal foi uma das grandes questões filosóficas que marcou o pensamento de Paul Ricoeur, conquanto ele percebeu que essa questão abrangia uma série de variáveis. O próprio autor experimentou dificuldades desde sua tenra infância com a perda de vários de seus familiares, tanto pelas guerras, quanto pelas doenças. Isso marcou sua percepção da realidade, ao mesmo tempo que o desafiou, como pensador contemporâneo, a tratar essas questões de forma séria e propositiva. Além dessas experiências familiares, ele foi convocado e combateu durante a Segunda Grande Guerra Mundial pelo exército francês, onde foi preso juntamente com seus companheiros e passou boa parte deste conflito em um campo de concentração designado para oficiais na Alemanha Nazista.

5 RICOEUR, Paul. Escritos e Conferências II: hermenêutica. Tradução de Lúcia Pereira de Souza. São Paulo: Edições Loyola, 2011. pp. 16-17.

6 RICOEUR, Paul. O Conflito das Interpretações: Ensaios de Hermenêutica. Tradução de M. F. Sá Correia. Porto: RÉS- Editora, 1988. pp. 291-292. 
A percepção da morte, da finitude, da maldade humana o fez cada vez mais escolher este como um campo prioritário de seu pensamento, sobretudo, na primeira fase, que vai da defesa de seu doutoramento ao início de sua carreira docente. Portocarrero aponta que "a escolha do seu campo filosófico de reflexão foi muito marcada- pelo problema do absurdo e pelo inverso da ação: o sofrimento. E acrescenta que tal escolha foi justamente feita numa altura em que ainda não conhecia a amplitude dos crimes nazis." Então, essa percepção da maldade e a tentativa de explicá-la e compreendê-la é fruto de um esforço intencional decorrente de sua própria experiência existencial.

Pensar acerca do mal é um dos problemas mais profundos lidados pelos pensadores das Ciências Humanas, ${ }^{8}$ porquanto são evidentes as limitações que o pensamento humano tem para perscrutar o que ocorre em meio a estes eventos. Se por um lado é evidente que a maldade manifesta-se nos mais diversos aspectos da experiência humana, por outro lado ela desafia aquelas pessoas que tentam pensar uma existência que não é condicionada apenas pelo fatalismo e pela inevitabilidade. Pois "o mal e o sofrimento que lhe é correlativo são o grande desafio à Teologia e à Filosofia, dado serem justamente o escândalo que revela o caráter inescrutável do existir e dos limites do pensamento lógico e reflexivo." Ricoeur fez em suas análises asserções com foco nas respostas filosóficas que são possíveis frente a problemática, apesar de em suas reflexões vários aspectos oriundos da Teologia estarem presentes, como ficará mais evidenciado na parte final desta reflexão que trata sobre a relação entre o símbolo e a religião.

As obras que mais se destacam sobre a temática são as que abordam a questão da Filosofia da Vontade, que é dividia em três volumes. O primeiro é Le volontaire et l'involontaire ${ }^{10}$ que é sua tese de doutorado. A segunda parte é dividida em dois volumes, Finitude et Culpabilité $e^{11}$

\footnotetext{
7 PORTOCARRERO, Maria Luísa. "Prefácio". In: RICOEUR, Paul. Simbólica do Mal. Tradução Hugo Barros e Gonçalo Marcelo. Lisboa: Edições 70, 2013. p. 7.

8 Geisteswissenschaften.

9 PORTOCARRERO, Maria Luísa. "Prefácio". In: RICOEUR, Paul. Simbólica do Mal. Tradução Hugo Barros e Gonçalo Marcelo. Lisboa: Edições 70, 2013. p. 8.

10 O Voluntário e o Involuntário.

11 Finitude e Culpabilidade.
} 
e La Symbolique du Mal. ${ }^{12}$ Existiria, inicialmente, uma última parte que nunca foi escrita pelo autor. ${ }^{13}$ A primeira obra dirige esforços para refletir acerca da relação de reciprocidade entre o agir voluntário e o agir involuntário, bem como aborda a dimensão existente entre decidir, agir e consentir. Isso leva a percepção de uma Antropologia em que o ser humano é visto como um ser desproporcionado, isto é, sempre à beira da tensão entre o agir bem, ou entre o fazer mal. Um ser de vontade falível, capaz de fazer escolhas más. É justamente nesta questão que é percebida a necessidade do símbolo, pois segundo Ricoeur só é possível analisar com profundida questões acerca do mal, da maldade, por meio deste. $\mathrm{O}$ autor prossegue, portanto, levantando questões como: a culpa, a confissão e o pecado, o que resulta numa "reflexão concreta, bem documentada do ponto de vista histórico e cultural, cujo interesse é simultaneamente antropológico, filosófico, histórico e religioso." 14

Pensar acerca do mal na cultura ocidental, segundo a ótica ricoeuriana, leva a reflexões que dialogam com o plano de fundo religioso e cultural desenvolvido nas civilizações, por meio de suas narrativas e construções históricas, contadas e construídas com intenção de dar sentido à existência social. Simbolizar, então, passa a ser imperativo ao ser humano em meio às suas limitações e incongruências. Por exemplo, o "símbolo do cativeiro, que transforma um acontecimento histórico (o cativeiro do Egito, depois o cativeiro da Babilônia) num esquema de existência, representa a expressão mais alta à qual teve acesso a experiência penitencial de Israel." ${ }^{15}$ E completa: "é graças a esta nova positividade do mal que o primeiro simbolismo, o da mancha, pode ser retomado: o esquema de exterioridade é encontrado, mas a um nível ético e já não mágico." ${ }^{16}$ Mostrando, dessa forma, as implicações filosóficas,

12 A Simbólica do Mal.

13 Cf. BARROS, Hugo; MARCELO, Gonçalo. "Nota dos Tradutores". In: RICOEUR, Paul. Simbólica do Mal. Tradução Hugo Barros e Gonçalo Marcelo. Lisboa: Edições 70, 2013. p. 12.

14 BARROS, Hugo; MARCELO, Gonçalo. "Nota dos Tradutores". In: RICOEUR, Paul. Simbólica do Mal. Tradução Hugo Barros e Gonçalo Marcelo. Lisboa: Edições 70, 2013. p. 13.

15 RICOEUR, Paul. O Conflito das Interpretações: Ensaios de Hermenêutica. Tradução de M. F. Sá Correia. Porto: RÉS- Editora, 1988. p. 287.

16 RICOEUR, Paul. O Conflito das Interpretações: Ensaios de Hermenêutica. Tradução de M. F. Sá Correia. Porto: RÉS- Editora, 1988. p. 287. 
teológicas e éticas que estão imbricadas na própria construção histórica de cada povo e civilização. $\mathrm{O}$ autor não pretende dizer com isso que toda a humanidade é mediada por estes mesmos símbolos, mas quer enfatizar que dentro de sua matriz cultural e civilizacional este é um dos marcos fundantes, se não o maior marco, para compreender o mal:

Para chegar ao concerto da vontade má, era preciso introduzir no círculo da reflexão o longo desvio dos símbolos e dos mitos, enfim, a mediação, ela mesma 'histórica', do mundo cultural. A Simbólica do Mal (1960) originou-se nessa confusão metodológica da vontade, afirma-se aqui, só se reconhece má, se confessa culpada, meditando acerca dos símbolos e dos mitos transmitidos pelas grandes culturas que instruíram a consciência ocidental, para calar sobre as outras culturas que não fazem parte da minha memória finita. ${ }^{17}$

Isso se desenvolve por meio de construções que geram significação e sentido para aquelas pessoas inseridas dentro daquela matriz simbólica, devido a esse fator, "antes de toda a Filosofia e [de] toda a Teologia está o caminho da explicitação. Como o disse noutro local, o símbolo dá que pensar. O mythos está no caminho do logos. Isto é verdade mesmo acerca da ideia arcaica de mancha."18 Símbolo esse que aponta para a necessidade humana de se confessar, de expurgar de sua existência as limitações que são advindas dessa compreensão. Ou seja, é intrínseco à humanidade a necessidade de encontrar soluções por meio dos mitos - das narrativas - que auxiliam na superação, ou ao menos na convivência, com esses comportamentos limitantes que são tão notoriamente expressos pela óbvia constatação de que o mal acompanha o ser humano no seu dia a dia em diversas esferas de sua experiência.

A obra La Symbolique du Mal expressa duas dimensões indissociáveis do símbolo, e, especificamente, da "mancha" e da "falta" que são expressões utilizadas pelo autor para explicitar seu pensamento sobre a temática, "na Simbólica do Mal, certamente, a maior parte de seu trabalho permanece dentro dos limites da linguagem, distinguindo sua parte simbólica da parte conceitual. Mas essa parte simbólica é

17 RICOEUR, Paul. Escritos e Conferências II: hermenêutica. Tradução de Lúcia Pereira de Souza. São Paulo: Edições Loyola, 2011. p. 18.

18 RICOEUR, Paul. O Conflito das Interpretações: Ensaios de Hermenêutica. Tradução de M. F. Sá Correia. Porto: RÉS- Editora, 1988. p. 417. 
inseparável do gesto a que se refere e da qual é a expressão verbal." 19 Com isso, o filósofo pretende expressar que a compreensão dos símbolos passa também por critérios objetivos e claros. Utilizando-se de uma abordagem fenomenológica com inserções hermenêuticas, por perceber que a dimensão polissêmica da questão leva, necessariamente, a novas metodologias e abordagens além da Fenomenologia.

Seu olhar inovador sobre o assunto constitui-se em grande originalidade, já que desenvolveu uma visão assentada no existencialismo cristão, como Marcel, ao mesmo tempo que ampliou a busca por novas saídas, legitimando questões interpretativas oriundas da Hermenêutica. Então, quando Ricoeur expõe seu pensamento sobre o mundo bíblico, "desenvolve o simbolismo do pecado, trabalha longamente nas interpretações dos rituais do sacrifício expiatório (...) [e visa] aderir aos mitos e seu significado como 'perdão'." ${ }^{20}$ Em outras palavras, a dimensão ritual auxilia na exposição e compreensão dos símbolos, posto que nos rituais geram-se novos sentidos que acolhem a polissemia. Por isso, "homem, fala e gesto, simbolismo e ritual, vão aparecer em sua falha constitutiva de um novo ângulo: entre gesto e fala, onde 'faça o que ele diz e diga o que faz' é uma expressão não da totalidade, mas da liberdade frágil." ${ }^{21}$ Dessarte, a humanidade é marcada por essas incongruências e fragilidades, que são explicitadas no gestual religioso permeado pelo simbolismo.

19 "Dans la Symbolique du mal. Certes, l'essentiel de son travail reste dans l'enceinte du langage, distinguant sa part symbolique de sa part conceptuelle. Mais cette part symbolique est indissociable du geste auquel elle renvoie et dont elle est l'expression verbale." CAUSSE. Guilhem. "La 'faille' chez Paul Ricoeur: De l'identité symbolique et narrative, à l'identité gestuelle et langagière”. In: Étude Ricoeuriennes. v. 9, n. 2, 2018. pp. 74-89. p. 79.

20 "Ricoeur ne nie pas la dimension rituelle présente dans le monde biblique: lorsqu'il élabore le symbolisme du péché, il travaille longuement les interprétations des rituels de sacrifice expiatoire. Il choisit cependant ici de ne plus y faire allusion, pour s'en tenir aux mythes et à leur signification comme 'pardon'." CAUSSE. Guilhem. "La 'faille' chez Paul Ricoeur: De l'identité symbolique et narrative, à l'identité gestuelle et langagière". In: Étude Ricoeuriennes. v. 9, n. 2, 2018. pp. 74-89. p. 82.

21 "L'homme, de la parole et du geste, du symbolique et du rituel, laisse alors apparaître as faille constitutive sous un nouvel angle: entre geste et parole, où "faire ce qu'il dit et dire ce qu'il fait" est expression non de totalité mais de fragile liberté." CAUSSE. Guilhem. "La 'faille' chez Paul Ricoeur: De l'identité symbolique et narrative, à l'identité gestuelle et langagière”. In: Étude Ricoeuriennes. v. 9, n. 2, 2018. pp. 74-89. p. 84. 
Outro aspecto fundamental na filosofia ricoeuriana é o horizonte metafórico que dá vez a chamada "via longa", na qual se pode explorar as significações e sentidos em maior profundidade. Entra em cena também a percepção da "poética" e da "ficção" que existem na linguagem, pois estas são mediadoras das construções humanas e servem de referenciais para as construções simbólicas. Com isso, a metáfora surge como um modelo que ajuda na redescrição da realidade; "portanto, a imagem apenas neutraliza a posição de realidade para liberar uma potência ontológica, um poder de dizer o ser, que para garantir a clareza só funciona sob a condição de suspensão realizada pelo imaginário." 22 Ou seja, esta potência polissêmica estocada no imaginário e na ficção fazem parte, constitutivamente, das construções humanas e ajudam na redescrição de questões profundas e aporéticas como o mal.

$\mathrm{Na}$ filosofia de Ricoeur o mal é tratado de forma simbólica, como vem sendo expresso neste artigo, assim, "o símbolo-coisa é, em potência, inúmeros símbolos falados que, por sua vez, se enredam numa manifestação singular de cosmos." ${ }^{.23}$ Devido a isso, sua manifestação dá-se das formas mais imprevisíveis possíveis. Embora uma das genialidades do filósofo seja ter sido perceber que as complexidades envolvidas no processo de compreensão do mal são balizadas pela percepção do ser humano de algumas marcas, como é o caso da "riqueza do simbolismo da mancha, mesmo quando esse simbolismo está plenamente interiorizado, é ainda o corolário do seu enraizamento cósmico." 24 Posto que dentro da cultura ocidental esse símbolo primevo manifesta-se de várias maneiras, que podem ser observadas pelo atento e acurado exame das Ciências Humanas.

Assim, uma das inovações metodológicas aperfeiçoadas por Ricoeur é a da diferenciação - utilizando-se a Hermenêutica - do que é mito e do que é símbolo. Pois apesar de ambos atuarem dentro de campos parecidos, suas expressões devem ser vistas como distintas pelo atento observador. Porque:

22 RICOEUR, Paul. "Cinco Lições: da linguagem à imagem”. In: Sapere Aude. Belo Horizonte, v. 4, n. 8, $2^{\circ}$ sem. 2013. pp. 13-36. p. 36.

23 RICOEUR, Paul. Simbólica do Mal. Tradução Hugo Barros e Gonçalo Marcelo. Lisboa: Edições 70, 2013. p. 27.

24 RICOEUR, Paul. Simbólica do Mal. Tradução Hugo Barros e Gonçalo Marcelo. Lisboa: Edições 70, 2013. p. 28. 
Entenderei sempre por símbolo, num sentido muito mais primitivo, as significações analógicas formadas espontaneamente e imediatamente doadoras de sentido; assim, a mancha análoga a nódoa, o pecado análogo a desvio, a culpabilidade análoga da acusação, todos esses símbolos estão ao mesmo nível que, por exemplo, o sentido da água como ameaça e como renovação no dilúvio e no batizado e, por último, que as hierofanias mais primitivas. Nesse sentido, o símbolo é mais radical que o mito. Entendemos por mito uma espécie de símbolo, qualquer coisa como símbolo desenvolvido em forma narrativa e articulado num tempo e num espaço que não podem ser coordenados, segundo o método crítico, ao tempo da história ou ao espaço do sagrado. ${ }^{25}$

Ou seja, o símbolo é anterior à expressão dos mitos e das narrativas que são desenvolvidas por ele. O símbolo é, devido a isso, detentor de maior profundidade ontológica, em razão dele ser gerador de múltiplos mitos e narrativas. Uma exemplificação dessa análise é o caso da "mácula", da "nódoa", ou da "mancha" como se denominou até aqui, que é a forma simbólica primeira, para Ricoeur, da expressão do mal e da finitude da vontade humana no Ocidente.

\section{Símbolo e a Hermenêutica}

Tendo sido abordado sobre o símbolo e o mal, agora passa-se a falar acerca de sua relação com a Hermenêutica. É notório observar que Ricoeur num primeiro momento de suas pesquisas filosóficas, focou apenas no método fenomenológico. Porém, o confronto com a questão do mal o levou a necessidade da interpretação do símbolo, e este, por sua vez, gerou a necessidade das análises hermenêuticas. Isso ocorreu pois o quadro polissêmico aberto pelo pensamento simbólico gerou a imprescindibilidade de uma ciência que possa dialogar com os símbolos sem reduzi-los. Justamente essa intenção de pensar de forma amplificadora e aberta a novos horizontes levou o filósofo a utilizar-se do método hermenêutico. Portanto, em seu desenvolvimento filosófico "a definição da Hermenêutica como interpretação dos símbolos ou expressões de duplo sentido nas quais pode ser decifrada a nossa pertença ontológica, segundo uma lógica do 'mostrado-escondido'."26 Isto levou a novas possibilidades interpretativas que contemplam o desvelamento,

25 RICOEUR, Paul. Simbólica do Mal. Tradução Hugo Barros e Gonçalo Marcelo. Lisboa: Edições 70, 2013. p. 34.

26 COSTA, Miguel Dias. "Prefácio". In: RICOEUR, Paul. O Conflito das Interpretações: Ensaios de Hermenêutica. Tradução de M. F. Sá Correia. Porto: RÉS- Editora, 1988. p. II. 
ao mesmo tempo que mantêm algo escondido; característica esta muito peculiar ao símbolo. Em outras palavras, "denomino símbolo toda expressão caracterizada pelo fenômeno do duplo sentido, segundo o qual a significação literal remete a um sentido segundo que só é acessível pelo retorno do sentido primeiro ao sentido segundo." 27

Para o autor falar dessa linguagem simbólica não é uma mera questão estética ou de figuração. Pois em suas concepções somente por meio da análise simbólica e metafórica é possível perceber a própria pertença humana em sua profundidade ontológica. Destacando que "mundo" ou "cosmos" é a construção, por meio da linguagem, que a humanidade faz para lidar consigo mesma e com o ambiente onde vive. "A realidade constitui-se simbolicamente na plurivocidade; entre nós e o mundo, entre nós e nós mesmos, coloca-se sempre a qualidade interpretativa dos símbolos que marcam o nosso enraizamento, a nossa pertença ao mundo, a uma cultura e a uma tradição." ${ }^{28}$ Essa pluralidade de olhares geradora de novas significações é cara ao seu método fenomenológico com inserções hermenêuticas. Sendo que "a hermenêutica e sua íntima relação com a linguagem formam o cerne dessas investigações, embora em retrospectiva possamos ver todos esses temas já antecipados em sua obra inicial." 29

Destaca-se que, para o autor, símbolo é toda a estrutura de significação no qual um "sentido direto, primário, literal, designa por acréscimo um outro sentido indireto, secundário, figurado, que apenas pode ser apreendido através do primeiro. Esta circunscrição das expressões com sentido duplo constitui precisamente o campo hermenêutico." 30 Informações estas preciosas ao melhor entendimento de porque essa relação ocorre em seu pensamento:

Só uma hermenêutica, instruída pelas figuras simbólicas, pode mostrar que essas diferentes modalidades da existência pertencem a uma única

27 RICOEUR, Paul. Escritos e Conferências II: hermenêutica. Tradução de Lúcia Pereira de Souza. São Paulo: Edições Loyola, 2011.p. 19.

28 COSTA, Miguel Dias. "Prefácio". In: RICOEUR, Paul. O Conflito das Interpretações: Ensaios de Hermenêutica. Tradução de M. F. Sá Correia. Porto: RÉS- Editora, 1988. p. III.

29 PELLAUER, David. Compreender Ricoeur. Tradução de Marcus Penchel. $2^{\mathrm{a}}$ edição. Petrópolis: Editora Vozes, 2010. p. 65.

30 RICOEUR, Paul. O Conflito das Interpretações: Ensaios de Hermenêutica. Tradução de M. F. Sá Correia. Porto: RÉS- Editora, 1988. p. 14. 
problemática, visto que são finalmente os símbolos mais ricos que asseguram a unidade dessas múltiplas interpretações; só eles possuem todos os vetores, regressivos e prospectivos, que as diversas hermenêuticas dissociam. Os verdadeiros símbolos estão cheios de todas as hermenêuticas, daquela que se dirige em direção à emergência de novas significações e daquela que se dirige para o ressurgimento dos fantasmas arcaicos. ${ }^{31}$

Nessa construção Ricoeur aponta para o fato de que existem duas abordagens complementares dentro de seu pensamento hermenêutico. Uma aponta para a simbólica arcaica e original, que leva o ser humano a refletir acerca de sua própria constituição enquanto ser e sociedade. Já a outra é geradora de novos sentidos, possibilitando, dessa maneira, o surgimento de novas compreensões e de uma ampliação do si, pela mediação do outro. Em outras palavras, essas "duas hermenêuticas: uma voltada para a emergência de símbolos novos, de figuras ascendentes, aspiradas como na Fenomenologia do Espírito, pela última, a qual já não é figura mas saber - a outra voltada para a ressurgência dos símbolos arcaicos." 32

Isso leva a uma das mais notórias asserções do autor sobre a temática, constituindo sua emblemática concepção: "o símbolo dá que pensar, faz apelo a uma interpretação, precisamente porque ele diz mais do que não diz e porque nunca acabou de dar a dizer." ${ }^{33}$ Isto é, quando se pensa por meio de mediações simbólicas não basta utilizar-se apenas das abordagens redutoras, que tendem a dar fim, dar limite a cada uma dos símbolos e arquétipos analisados. Pelo contrário, o símbolo deve ser compreendido hermeneuticamente pelo conhecimento humano. Pois por meio da ciência das interpretações é possível apresentar as dificuldades e limitações do pensamento humano, indo o mais longe possível, porém sem esgotar a totalidade dos sentidos e significações de temas aporéticos. E, nessa questão, apreende-se porque "a hermenêutica deixa de ter um âmbito restrito à exegese para passar a ser uma investigação

31 RICOEUR, Paul. O Conflito das Interpretações: Ensaios de Hermenêutica. Tradução de M. F. Sá Correia. Porto: RÉS- Editora, 1988. pp. 25-26.

32 RICOEUR, Paul. O Conflito das Interpretações: Ensaios de Hermenêutica. Tradução de M. F. Sá Correia. Porto: RÉS- Editora, 1988. p. 117.

33 RICOEUR, Paul. O Conflito das Interpretações: Ensaios de Hermenêutica. Tradução de M. F. Sá Correia. Porto: RÉS- Editora, 1988. p. 29. 
filosófica e narrativa sobre o ato de constituição do sentido." ${ }^{34}$ Ou seja, ela ganha o estatuto de uma ciência de primeira instância que não é utilizada apenas como auxiliar na interpretação de textos clássicos, jurídicos ou religiosos.

Quando o filósofo francês opta por este caminho - da "via longa" ele contribui de forma significativa para o pensamento contemporâneo, posto que levou ao alargamento das interpretações filosóficas dentro de seu método. Uma das características mais destacadas do autor é que ele dialogou profundamente com a erudição dos temas e autores de sua época, possibilitando, assim, uma rica síntese construtora de novos horizontes para as Ciências Humanas, para a Filosofia, ou mesmo para as Ciências da Religião. Seu pensamento centrado na Hermenêutica, e esta como uma teoria da interpretação, constituiu-se numa passagem de uma hermenêutica dos símbolos para uma hermenêutica do discurso. "Consideramos que esta transição constitui uma ampliação do processo metodológico do autor e uma confirmação da sua via longa, em oposição à via curta levada a cabo pela fenomenologia husserliana e heideggeriana." 35 Isto é, esta concepção insere a Hermenêutica sistematicamente na Fenomenologia como um estágio último, levando ao alargamento das abordagens pela chamada "via longa", privilegiando o pensamento complexo sem tentar reduzi-lo a um número pequeno de variáveis, que apesar de parecer gerar soluções cabais num primeiro momento, na prática acaba por empobrecer as percepções humanas sobre si e sobre sua constituição social e ética.

Ricoeur denominou de filosofias da suspeita as formas de pensamento que privilegiam a redução dos elementos abordados na análise filosófica. Estas abarcam desde pensadores que vão para o novo campo da psicanálise, que ainda estava se desenvolvendo em sua época; passando por pensadores sociais; chegando até um dos mais famosos niilistas da contemporaneidade:

34 TAVARES, Manuel. "Paul Ricoeur e um novo conceito de interpretação: da hermenêutica dos símbolos à hermenêutica do discurso". In: Veritas. Porto Alegre, v. 63, n. 2, maio-ago. 2018. pp. 436-457. p. 445.

35 TAVARES, Manuel. "Paul Ricoeur e um novo conceito de interpretação: da hermenêutica dos símbolos à hermenêutica do discurso". In: Veritas. Porto Alegre, v. 63, n. 2, maio-ago. 2018. pp. 436-457. p. 437. 
Pouco importa como, partindo do tema da culpabilidade, em sua determinidade precisa, abriu-se a questão da pluralidade e do conflito das interpretações. Penetrando no confronto de Freud com a tradição, percebemos que se tratava de um conflito entre duas hermenêuticas, uma amplificadora, no sentido citado acima, e outra da suspeita, na qual Freud figurava ao lado de outros mestres da suspeita, Feuerbach, Marx e principalmente Nietzsche. ${ }^{36}$

O filósofo francês também divergiu de outras correntes proeminentes do pensamento do século XX, como o estruturalismo - apesar de conhecer muitos aspectos da corrente citada. Em sua obra compilada sobre o título de Escritos e Conferências II, ele afirma "nada menos que o destino da questão do sujeito e da compreensão de si. Enquanto o estruturalismo se assemelhava a uma apologia para um funcionamento anônimo, no sentido mais forte do termo de sistemas de signos sem ancoragem subjetiva." ${ }^{37}$ Denotando, assim, a diferença entre a proposta ricoeuriana e as abordagens estruturalistas, pois para Ricoeur a dimensão do sentido é inseparável do papel mediador que é exercido pelos sistemas em sua relação com a compreensão de si. E completa com sua asserção em Du texte à L'action: ${ }^{38 ~ " n a ̃ o ~ e x i s t e ~ c o m p r e e n s a ̃ o ~ d e ~ s i ~ q u e ~}$ não seja intermediada por signos, símbolos e textos; a compreensão de si coincide, em última análise, com a interpretação aplicada a esses termos mediadores'." 39

Ricoeur ocupou um privilegiado espaço na tradição hermenêutica, pois além de divulgar "filósofos como Schleiermacher, Dilthey, Heidegger ou Gadamer, quer como autor original que contribuiu de forma ímpar para a renovação da filosofia hermenêutica." ${ }^{40}$ Sendo que suas análises o levaram a novas saídas e novas intepretações. Uma das principais diferenças dele em relação a estes autores é o fato de integrar a

36 RICOEUR, Paul. Escritos e Conferências II: hermenêutica. Tradução de Lúcia Pereira de Souza. São Paulo: Edições Loyola, 2011. pp. 22-23.

37 RICOEUR, Paul. Escritos e Conferências II: hermenêutica. Tradução de Lúcia Pereira de Souza. São Paulo: Edições Loyola, 2011. p. 23.

38 Do Texto à Ação.

39 RICOEUR, Paul. Du texte à l'action. Essais d'herméneutique, II. Paris: Editions du Seuil, 1986. p. 29.

40 BARROS, Hugo; MARCELO, Gonçalo. "Nota dos Tradutores". In: RICOEUR, Paul. Simbólica do Mal. Tradução Hugo Barros e Gonçalo Marcelo. Lisboa: Edições 70, 2013. p. 11. 
compreensão e a explicação como dois momentos que ocorrem dentro da mesma análise, dizendo:

O momento da compreensão caracteriza-se por uma apreensão intuitiva e global do que é abordado nesse campo, por uma antecipação de sentido que roça a adivinhação, por um engajamento do sujeito conhecedor; o momento da explicação por outro lado, é marcado pela predominância da análise, da subordinação do caso particular a regras, leis ou estruturas, pelo distanciamento do objeto de estudo em relação a um sujeito não implicado. O importante, a meu ver, é não separar a compreensão da explicação e vice-versa. ${ }^{41}$

Com isso, compreensão e explicação acabam por se constituir como dois momentos de grande densidade. Explicação e compreensão integram seu método de forma marcante, pois todo seu desenvolvimento posterior contará com as ricas análises de seu método conjugador destes dois momentos. Metodologia essa que ganha ainda mais destaque por ele ter tido a notória capacidade de dialogar com tantos pensadores e correntes de pensamento. Por esse motivo a compreensão constitui-se "dialeticamente oposta ao polo de explicação em toda ciência interpretativa, e constitui o índice não mais metodológico, mas adequadamente a veritativa relação ontológica de pertencimento do nosso ser aos seres e ao Ser." ${ }^{42}$ Essa maneira de integrar seu pensamento filosófico manifesta-se na percepção de que "explicar mais é compreender melhor. Ou seja, se a compreensão precede, acompanha e envolve a explicação, esta em troca desenvolve analiticamente a compreensão." 43

41 RICOEUR, Paul. Escritos e Conferências II: hermenêutica. Tradução de Lúcia Pereira de Souza. São Paulo: Edições Loyola, 2011. p. 24.

42 "Dialectiquement opposé au pôle de l'explication dans toute science interprétative, et constitue l'indice non plus méthodologique mais proprement véritatif de la relation ontologique d'appartenance de notre être aux êtres et à l'Être.” RICOEUR, Paul. "Expliquer et comprendre: Sur quelques connexions remarquables entre la théorie du texte, la théorie de l'action et la théorie de l'histoire". In: Revue Philosophique de Louvain, v. 75, n. 25, 1977. pp. 126-147. p. 145.

) RICOEUR, Paul. Escritos e Conferências II: hermenêutica. Tradução de Lúcia Pereira de Souza. São Paulo: Edições Loyola, 2011.. 26. 


\section{Símbolo e a Religião}

É interessante observar os pressupostos nos quais o autor francês desenvolveu sua obra, posto que ela foi desenvolvida, sobretudo, durante a segunda metade do século XX. Ricoeur não objetivava uma filosofia religiosa, ele "não se denomina um filósofo cristão, mas, antes de tudo, um filósofo por excelência. Devido a herança cristã na formação do filósofo, não deveríamos confundir que Ricoeur buscou ou propôs uma filosofia cristã." 44 Porém, isso não significa que sua obra não dialogou com temas teológicos, ou mesmo que muitas de suas preocupações não tivessem relação com questões religiosas.

Sua abordagem partia de pressupostos da Filosofia, isto é, sem dar privilégios metodológicos a absolutos que pudessem comprometer seu pensamento. Então, "entre o filosófico e o religioso não há nem confusão, nem separação," ${ }^{45}$ fórmula essa endossada por François Dosse em sua obra que fala sobre a vida de Ricoeur. Desde os primórdios de sua obra filosófica, como em La Simbolique du Mal, desenvolveu-se um pensamento que alicerçava-se nos símbolos oriundos da Teologia cristã, e em "trabalhos posteriores, como Freud e Filosofia (De l'interpretation, essai sur Freud ${ }^{46}, 1965^{47}$ ), reiteraram essa perspectiva no contexto do que Paul Ricoeur chamou de 'fenomenologia da religião'."48

Dito isso, pode-se refletir acerca de uma das interpretações ricoeurianas acerca do símbolo e sua interação com temas religiosos. Um dos simbolismos mais evidentes no mundo ocidental para o autor é o do primeiro homem, conforme narrado nas primeiras páginas da Bíblia, livro sagrado que embasa a tradição judaico-cristã:

44 SOUZA, Vitor Chaves. O Ser e o Além do Ser: a dobra da religião em Paul Ricoeur. 2015. 246p. Doutorado em Ciências da Religião - Faculdade e Humanidades e Direito. São Bernardo do Campo: Universidade Metodista de São Paulo - Umesp. p. 37.

45 Cf. DOSSE, François. Paul Ricoeur: Les sens d'une vie (1913-2005). Paris: La Découverte, 2008.

46 Da Interpretação, ensaio sobre Freud.

47 Cf. RICOEUR, Paul. De l'interprétation. Essai sur Freud. Paris: Éditions du Seuil, 1965.

48 "Later Works such as Freud and Philosophy (De l'interprétation, essai sur Freud, 1965), reiterated this perspective in the framework of what Paul Ricoeur termed a 'phenomenology of religion'." BARASH, Jeffrey Andrew. "The Time of Collective Memory: Social Cohesion and Historical Discontinuity in Paul Ricoeur's Memory, History, Forgetting”. In: Étude Ricoeuriennes. v. 10, n. 1, 2019. pp. 102-111. p. 105. 
Esta tripla descrição, que o homem moderno pode articular, cristaliza no símbolo de um 'antes' que vem recolher o mito do primeiro homem. Estamos aqui na fonte do esquema da herança que encontramos na base da especulação adâmica, de são Paulo a santo Agostinho. Mas o sentido deste esquema apenas aparece se se renuncia inteiramente projetar na história a figura adâmica, se o interpretamos como um 'tipo', como 'o tipo do homem velho'. Aquilo que não se deve fazer é a passagem do mito à mitologia. Nunca se dirá o bastante o mal que fez à cristandade a interpretação literal, seria preciso dizer 'historicista' (...) Simultaneamente, o tesouro escondido no símbolo adâmico foi delapidado; o espírito forte, o homem racional, de Pelágio, Kant, Feuerbach, Marx ou Nietzsche, terá sempre razão contra a mitologia, enquanto que o símbolo dará sempre que pensar para além de toda a crítica redutora. Entre o historicismo ingênuo fundamentalista e o moralismo exangue do racionalismo, abre-se a vida da hermenêutica dos símbolos. ${ }^{49}$

Com isso, percebe-se que Ricoeur dialoga com a rica tradição religiosa e cultural que molda muitas das concepções do ser humano ocidental moderno, mesmo daqueles que se consideram irreligiosos. Pois estes símbolos perpassam pelas esferas da constituição identitária do sujeito, influenciando a linguagem e as relações humanas que decorrem dessas inteirações múltiplas e complexas. Deve-se observar, então, que o símbolo tem sua abordagem iniciada em La Simbolique $d u$ Mal, porém ela se amplia e passa a articular-se com uma série de desenvolvimentos de sua obra. Um dos progressos de suas pesquisas aborda a diferenciação entre símbolo e mito, como já foi demonstrado. Exemplifica-se: “o exílio é o símbolo primário da alienação humana, mas a história da expulsão de Adão e Eva do Paraíso é uma narrativa mítica de segundo grau que coloca em cena personagens, lugares, um tempo, episódios fabulosos." ${ }^{50}$ Isto é, o símbolo antecede o mito, embasando-o, mas o primeiro é mais abrangente do que o segundo, pois de um mesmo símbolo podem surgir diferente narrativas míticas. Sendo que a definição de mito no modelo ricoeuriano é bastante distinta da descrição que muitas abordagens redutoras têm sobre o assunto:

49 RICOEUR, Paul. O Conflito das Interpretações: Ensaios de Hermenêutica. Tradução de M. F. Sá Correia. Porto: RÉS- Editora, 1988. pp. 279-280.

50 RICOEUR, Paul. Escritos e Conferências II: hermenêutica. Tradução de Lúcia Pereira de Souza. São Paulo: Edições Loyola, 2011. p. 20. 
Não [é] uma falsa explicação através de imagens e fábulas, mas uma narrativa tradicional sobre acontecimentos que tiveram lugar na origem dos tempos, destinada a fundar a ação ritual dos homens nos dias de hoje e, de maneira geral, a instituir todas as formas de ação e de pensamento através das quais o homem se compreende a si mesmo no seu mundo. ${ }^{51}$

Outro arquétipo muito conhecido e fundamental para a constituição do ser humano ocidental, e que tem relação com o desenvolvimento do pensamento simbólico e religioso em Ricoeur, são suas asserções acerca daquilo que "o símbolo de Adão transmite, e primeiro que tudo e essencialmente esta afirmação de que o homem é, senão a origem absoluta, pelo menos o ponto de emergência do mal no mundo." 52 Isto é, por meio dessa narrativa justifica-se a origem do mal no mundo, problema este abordado com afinco pelo filósofo e que foi base da primeira parte desse artigo. Em Le conflit des interprétations - Essais d'herméneutique ${ }^{53}$ ele afirma: "por meio destes símbolos mais descritivos do que explicativos, os escritores bíblicos visavam certos traços obscuros e obsidiantes da experiência humana do mal, que não podem ser admitidos no conceito puramente negativo de falta." 54

Quando aborda-se acerca do mal, o traço religioso da confissão de pecados, expressa a falibilidade e a maldade inerente ao ser humano. Embora Ricoeur destaque que quando ocorre a confissão, existe a possibilidade de uma vontade boa surgir, por meio de escolhas éticas. Isso não significa que não existam limitações ou falhas, mas essas construções narrativas religiosas descrevem muito da experiência humana, tanto em nível individual quanto coletivo. Por isso, "a experiência que é confessada pelo crente na confissão de pecados suscita, em virtude da sua própria estranheza, a linguagem; a experiência de se ser si mesmo e de, ao mesmo tempo, se estar alienado de si." ${ }^{55}$ Isto é, quando ocorre a confissão o fato

51 RICOEUR, Paul. Simbólica do Mal. Tradução Hugo Barros e Gonçalo Marcelo. Lisboa: Edições 70, 2013. p. 21.

52 RICOEUR, Paul. O Conflito das Interpretações: Ensaios de Hermenêutica. Tradução de M. F. Sá Correia. Porto: RÉS- Editora, 1988. p. 268.

53 Conflito das Interpretações. Ensaios de Hermenêutica.

54 RICOEUR, Paul. O Conflito das Interpretações: Ensaios de Hermenêutica. Tradução de M. F. Sá Correia. Porto: RÉS- Editora, 1988. p. 277.

55 RICOEUR, Paul. Simbólica do Mal. Tradução Hugo Barros e Gonçalo Marcelo. Lisboa: Edições 70, 2013. p. 24. 
é transcrito do plano da linguagem para o sentido existencial, sublimando, assim, o pecado - que é a alienação de si para o autor.

Em Ricoeur o símbolo original da "mancha" é antecessor de outros desenvolvimentos posteriores que marcaram profundamente as constituições sociais e religiosas. Um dos exemplos mais evidentes disso é o desenvolvimento de concepções teológicas que desenvolvem o símbolo original, isso ocorre, por exemplo, em Agostinho quando este sintetiza a noção de pecado original, marcando indelevelmente a forma como a Teologia, e mesmo a Filosofia passaram a abordar a temática. Pois "muitas filosofias, clássicas e modernas, assumem como 'dado' religioso, teológico, esse suposto conceito e reduzem o problema filosófico da culpa a crítica da ideia de pecado original." ${ }^{56}$ Com isso, muito do que é desenvolvido sobre o assunto já é um dado decorrente dessa interpretação posterior, que gerou toda uma conceituação teológica implicadora para as tradições filosóficas, antropológicas e históricas desenvolvidas no seio do mundo ocidental.

\section{Considerações Finas}

Concluindo, este artigo demonstra as interações e o desenvolvimento de uma das principais temáticas do pensamento filosófico ricoeuriano, sua abordagem sobre o símbolo e suas consequências em algumas áreas, tais como: o mal, a hermenêutica e a religião. Sua compreensão de que “o símbolo dá que pensar (...) [a] partir de um simbolismo já constituído, é dar-se o que pensar; mas é também, ao mesmo tempo, introduzir uma contingência radical no discurso." ${ }^{57}$ Mostra que o símbolo acaba por entrar em suas reflexões não como questão metodológica a priori, mas adentra quando a aporética do mal é apresentada. Levando-o a perceber a incompletude do método fenomenológico husserliano para pensar questões complexas e simbólicas. Com isso, surge a necessidade de analisar os arquétipos que são desenvolvidos em mitos e narrativas constituídos simbolicamente; e a inserção hermenêutica contempla a possibilidade de melhor explicar e compreender o mal. Sendo a expli-

56 RICOEUR, Paul. Simbólica do Mal. Tradução Hugo Barros e Gonçalo Marcelo. Lisboa: Edições 70, 2013. pp. 20-21.

57 RICOEUR, Paul. Simbólica do Mal. Tradução Hugo Barros e Gonçalo Marcelo. Lisboa: Edições 70, 2013. p. 36. 
cação e a compreensão momentos complementares da mesma análise, e não mais usados distintamente como ocorria em Dilthey.

Outro traço fundamental de seu pensamento está na percepção de que o leitor, ou aquele que entra em contato com o texto, seja este oral ou escrito, contribui de forma indelével para a modificação dos sentidos e dos significados das questões interpretadas, impondo ao ser humano o encontro com sua:

Memória cultural (...) o encontro da fonte judaica com a origem grega é a interseção fundamental e fundadora da nossa cultura; a fonte judaica é o primeiro 'outro' da filosofia, o seu outro mais 'próximo', o fato abstratamente contingente desse encontro é o próprio destino da nossa existência ocidental..$^{58}$

Ou seja, só é possível desenvolver conhecimento partindo dos pressupostos que são dados por meio dessas memórias coletivas, tanto religiosas quanto sociais. Destacando que as sociedades arcaicas sempre tiveram a religiosidade profundamente imbricada em suas relações sociais, éticas e políticas. E mesmo as sociedades ditas modernas e laicizadas, conforme mostra o autor, ainda são em grande medida influenciadas por questões de ordem religiosa, por meio dos símbolos e mitos que constituem as narrativas das identidades de si. Devido a esses fatos, "eis porque a história da consciência de culpa da Grécia e em Israel será constantemente a nossa referência central: é a nossa origem mais 'próxima', nessa economia espiritual da distância." 59

Portanto, ao mesmo tempo que perceber estes arquétipos e símbolos originais auxiliam na intepretação das profundezas existenciais, estes também marcam quais são as limitações que uma determinada sociedade tem na compreensão de si e de outras civilizações. Isso ocorre porque sua abordagem fenomenológica com inserções hermenêuticas é orientada por problematizações filosóficas de origem grega, além de serem marcadas pelas experiências judaicas e cristãs. Sendo assim, não é possível "fazer justiça às grandes experiências da Índia e da China.

58 RICOEUR, Paul. Simbólica do Mal. Tradução Hugo Barros e Gonçalo Marcelo. Lisboa: Edições 70, 2013. p. 36.

59 RICOEUR, Paul. Simbólica do Mal. Tradução Hugo Barros e Gonçalo Marcelo. Lisboa: Edições 70, 2013. p. 36. 
E é aqui que se tornam evidentes não só a contingência da nossa tradição como também seu limite. Há um momento no qual o princípio de orientação se torna princípio de limitação." ${ }^{\circ 0}$ Uma vez que, enquanto seu método desvela grandes possibilidades na construção filosófica, ele também acaba por demonstrar que existem limitações intrínsecas ao próprio sistema, posto que outras culturas conterão outros símbolos, arquétipos, mitos e narrativas. Levando a necessidade de outros desenvolvimentos filosóficos, que contemplem a compreensão destes de forma peculiar a sua própria memória cultural, social, identitária, filosófica e religiosa.

\section{Referências}

BARASH, Jeffrey Andrew. "The Time of Collective Memory: Social Cohesion and Historical Discontinuity in Paul Ricoeur's Memory, History, Forgetting". In: Études Ricoeuriennes. v. 10, n. 1, 2019. pp. 102-111.

BARROS, Hugo; MARCELO, Gonçalo. "Nota dos Tradutores". In: RICOEUR, Paul. Simbólica do Mal. Tradução Hugo Barros e Gonçalo Marcelo. Lisboa: Edições 70, 2013.

CAUSSE. Guilhem. "La 'faille' chez Paul Ricoeur: De l'identité symbolique et narrative, à l'identité gestuelle et langagière". In: Études Ricoeuriennes. v. 9 , n. 2, 2018. pp. 74-89.

COSTA, Miguel Dias. "Prefácio". In: RICOEUR, Paul. O Conflito das Interpretações: Ensaios de Hermenêutica. Tradução de M. F. Sá Correia. Porto: RÉS- Editora, 1988.

DOSSE, François. Paul Ricoeur: Les sens d'une vie (1913-2005). Paris: La Découverte, 2008.

GENTIL, Hélio. "Paul Ricoeur e o desafio do sentido". In: CARDIM, Leandro Neves. Tópicos de filosofia francesa contemporânea. Curitiba: Editora UFPR, 2014.

MENDES, Breno. Existência e Linguagem: o problema do sentido na Filosofia da História de Paul Ricoeur. 2019. 301p. Doutorado em História - Faculdade de Filosofia e Ciências Humanas. Belo Horizonte: Universidade Federal de Minas Gerais - UFMG.

PELlAUER, David. Compreender Ricoeur. Tradução de Marcus Penchel. $2^{\mathrm{a}}$ edição. Petrópolis: Editora Vozes, 2010.

60 RICOEUR, Paul. Simbólica do Mal. Tradução Hugo Barros e Gonçalo Marcelo. Lisboa: Edições 70, 2013. p. 39. 
PORTOCARRERO, Maria Luísa. "Prefácio". In: RICOEUR, Paul. Simbólica do Mal. Tradução Hugo Barros e Gonçalo Marcelo. Lisboa: Edições 70, 2013. RICOEUR, Paul. "Cinco Lições: da linguagem à imagem". In: Sapere Aude. Belo Horizonte, v. 4, n. 8, $2^{\circ}$ sem. 2013. pp. 13-36.

. De l'interprétation. Essai sur Freud. Paris: Éditions du Seuil, 1965. du Seuil, 1986.

. Du texte à l'action. Essais d'herméneutique, II. Paris: Editions

. Escritos e Conferências II: hermenêutica. Tradução de Lúcia Pereira de Souza. São Paulo: Edições Loyola, 2011.

. "Expliquer et comprendre: Sur quelques connexions remarquables entre la théorie du texte, la théorie de l'action et la théorie de l'histoire"'. In: Revue Philosophique de Louvain, v. 75, n. 25, 1977. pp. 126-147.

O Conflito das Interpretações: Ensaios de Hermenêutica. Tradução de M. F. Sá Correia. Porto: RÉS- Editora, 1988.

. Simbólica do Mal. Tradução Hugo Barros e Gonçalo Marcelo. Lisboa: Edições 70, 2013.

SOUZA, Vitor Chaves. O Ser e o Além do Ser: a dobra da religião em Paul Ricoeur. 2015. 246p. Doutorado em Ciências da Religião - Faculdade e Humanidades e Direito. São Bernardo do Campo: Universidade Metodista de São Paulo - Umesp.

TAVARES, Manuel. "Paul Ricoeur e um novo conceito de interpretação: da hermenêutica dos símbolos à hermenêutica do discurso". In: Veritas. Porto Alegre, v. 63, n. 2, maio-ago. 2018. pp. 436-457. 